\title{
Removal of Herbicides from Water Using Heterogeneous Photocatalysis Case Study: MCPA Sodium Monohydrate
}

\author{
Samer Khalaf1,2*, Jawad H. Shoqeir'1, Laura Scrano3, Rafik Karaman4, Sabino A. Bufo², \\ Tonni Agustiono Kurniawan ${ }^{5}$
}

${ }^{1}$ Soil \& Hydrology Research Lab (SHR), Department of Earth and Environmental Sciences, Al-Quds University, Jerusalem, Palestine

${ }^{2}$ Department of Science, University of Basilicata, Potenza, Italy

${ }^{3}$ Department of European Cultures (DICEM), University of Basilicata, Potenza, Italy

${ }^{4}$ Department of Bioorganic Chemistry, Faculty of Pharmacy, Al-Quds University, Jerusalem, Palestine

${ }^{5}$ Key Laboratory of the Coastal and Wetland Ecosystems (Xiamen University), Ministry of Education, College of the Environment and Ecology, Xiamen University, Fujian, China

Email: *skhalaf@staff.alquds.edu, samer.m.khalaf@gmail.com

How to cite this paper: Khalaf, S., Shoqeir, J.H., Scrano, L., Karaman, R., Bufo, S.A. and Kurniawan, T.A. (2019) Removal of Herbicides from Water Using Heterogeneous Photocatalysis Case Study: MCPA Sodium Monohydrate. Journal of Water Resource and Protection, 11, 1024-1035. https://doi.org/10.4236/jwarp.2019.118060

Received: July 1, 2019

Accepted: August 19, 2019

Published: August 22, 2019

Copyright $\odot 2019$ by author(s) and Scientific Research Publishing Inc. This work is licensed under the Creative Commons Attribution International License (CC BY 4.0).

http://creativecommons.org/licenses/by/4.0/

\begin{abstract}
In this study, the herbicide MCPA sodium salt monohydrate (sodium (4-chloro-2 methylphenoxy) acetate has been studied as are presentative compound used in the agricultural field. Accordingly, direct photolysis and photocatalytic experiments under artificial irradiation simulating solar light in laboratorial conditions were performed. Photocatalytic experiments were performed using $\mathrm{TiO}_{2}$ dispersed powder and as an immobilized thin layer on the surface of blue glasses. The obtained results of photolysis showed a poor efficacy toward degradation of MCPA sodium monohydrate, with half-life $\left(t_{1 / 2}\right) 6931.5 \mathrm{~min}$. While, the addition of $\mathrm{TiO}_{2}$ dispersed powder to the photocatalytic process enhances the process dramatically with $\left(\mathrm{t}_{1 / 2}\right)$ equal to 36.5 min; furthermore, complete mineralization had been reached after approximately 4 hours, whereas the addition of $\mathrm{TiO}_{2}$ through immobilized system led to enhance the degradation rate with $2236 \mathrm{~min}$. as $\mathrm{t}_{1 / 2}$. In spite of this, using $\mathrm{TiO}_{2}$ supported on glass substrates with more improvements could be a promising alternative to conventional $\mathrm{TiO}_{2}$ suspension, and provides a clean treatment method.
\end{abstract}

\section{Keywords}

Anti-Inflammatory Drugs, Advanced Oxidation Process, Wastewater, Photocatalysis, $\mathrm{TiO}_{2}$, Photo-Degradation, MCPA 


\section{Introduction}

The pollution of the aquatic environment by different contaminants such as (herbicides, fungicides, etc.) has gained increasing attention recently due to the frequent and wide uses of these chemicals in the agricultural activities [1]. Using pesticides has a lot of benefits such as increasing crop production, suppressing plant and animal pests and to protect agriculture products [2]. However, pesticides even if applied at the recommended doses, can induce environmental pollution especially for groundwater and surface waters [3] [4]. According to the European Water Framework directives (WFD), the amount of a single pesticide compound in drinkable water cannot exceed $0.1 \mu \mathrm{g} \cdot \mathrm{L}^{-1}$, and the total pesticide content must remain lower than $0.5 \mu \mathrm{g} \cdot \mathrm{L}^{-1}$ [5]. Therefore, such contaminants should be removed by using nonconventional treatment processes to reduce the risk of water pollution. During last decade advanced oxidation processes (AOPs) have been classified as a promising way to decrease the content, or even to remove completely the pesticides from water [6] [7]. By using AOPs, the organic compounds can be completely mineralized to carbon dioxide and water mostly by hydroxyl radicals (HO) [8]. AOPs include several technologies such as photolysis, ozonation, photocatalysis, photo-Fenton and sonolysis [9]. Among AOPs techniques, heterogeneous photocatalysis is the most applied technique in the last decades regarding organic pollutants removal from water [10] [11].

As reported by Zhu et al. (2005), during the heterogeneous photo-catalysis process, dispersed solid particles of semiconductor efficiently absorb large fractions of the UV spectrum, and they generate chemical oxidants from dissolved oxygen or water in situ, these chemical oxidants activate the degradation of contaminants until the total mineralization [10].

Among the various semiconductors employed, $\mathrm{TiO}_{2}$ is the most preferable material for the photo-catalytic process [11] due to its high photosensitivity, non-toxic nature, large band gap, chemical stability and lower cost [12]. In heterogeneous, photocatalysis titanium dioxide could be used in different forms, as a suspended powder or immobilized over glass substrates.

In this study, the herbicide MCPA sodium salt monohydrate (sodium (4-chloro-2 methylphenoxy) acetate (Figure 1) acetate was chosen and studied as are presentative model compound of an organic pollutant class usually used in agricultural field [13] [14].

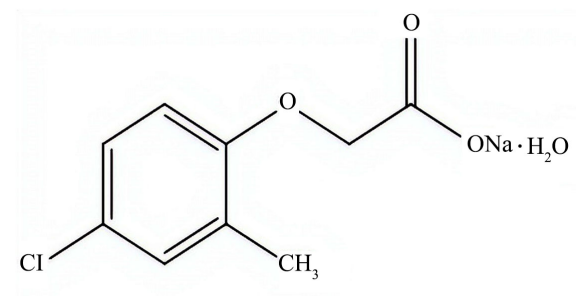

MCPA Sodium monohydrate

Figure 1. Chemical structure of MCPA sodium monohydrate. 
The aims of this work are to evaluate the efficacy of two oxidation processes (Photolysis and heterogeneous photocatalysis using a solar simulator light) towards the removal of MCPA sodium monohydrate from aqueous phase. As well, to evaluate the efficiency of using $\mathrm{TiO}_{2}$ immobilized on blue glass slabs. This approach aims to circumvent the need for filtration to recover the catalyst from the reaction mixture and decrease the operational costs necessary to recover the powder.

\section{Materials and Methods}

\subsection{Materials}

The herbicide MCPA sodium salt monohydrate (sodium (4-chloro-2 methylphenoxy) acetate pure standard (99\% purity) was purchased from Sigma-Aldrich Corporation (USA) and used as received. Formic acid and HPLC grade Acetonitrile were purchased from Aldrich and used as received. Water was Milli-Q quality. $\mathrm{TiO}_{2}$ P-25 from Degussa (anatase/rutile $=3.6 / 1$, surface area $50 \mathrm{~m}^{2} / \mathrm{g}$, non-porous) was used for photo-catalytic experiments. Grafted $\mathrm{TiO}_{2}$ thin blue glasses were obtained from Pilkington (UK) (Figure 2). All the solutions were daily prepared in ultra-pure water from a Millipore purification system. The $\mathrm{pH}$ of the solution was monitored using a Basic $\mathrm{pH}$ Meter from Denver Instrument Company. In the experiments with heterogeneous was separated by filtration (through $0.2 \mu \mathrm{m}$ membrane filters, Schleicher and Schuell, Germany. Cat. No. 10462200 ) before analysis of MCPA sodium salt monohydrate.

\subsection{Equipments}

Photolysis, photocatalysis with $\mathrm{TiO}_{2}$ powder and photocatalysis with immobilized $\mathrm{TiO}_{2}$ on thin blue glass experiments were accomplished using batch reactor system, this system consists of:

1) Suntest CPS + Solar Simulator (Heraeus Instruments, Germany) equipped with a xenon lamp, temperature sensor and water-cooling circuit. The xenon lamp was filtered by an optically stable borosilicate UV filter (Atlas Material Testing, France) delivering a light emission spectrum similar to that of the sun with a UV cut-off at $290 \mathrm{~nm}$. The pyrex reactor that contains the solution placed inside the chamber of the suntest device.

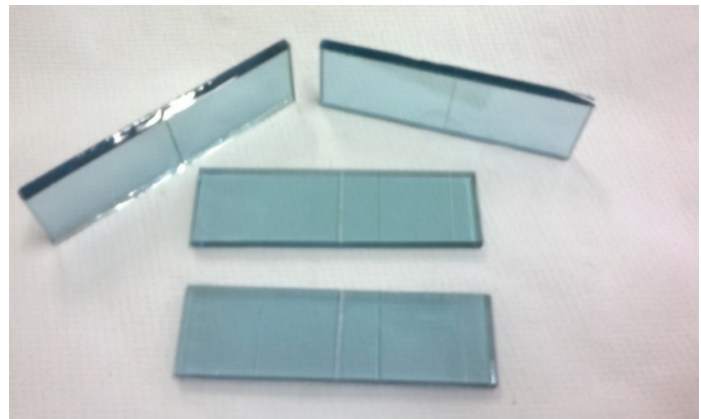

Figure 2. Grafted $\mathrm{TiO}_{2}$ thin blue glasses. 
2) Pyrex batch reactor. The capacity of the reactor is $300 \mathrm{ml}$. Its outer perimeter reactor is covered by aluminum foils and only the upper surface is exposed to radiation.

3) Magnetic stirrer device (Falc F20 Mini Magnetic stirrer. Progen Scientific, Merton. London) is employed to maintain a continuous stirring for the solution inside the pyrex reactor during the experiments.

A schematic drawing of the batch reactor system is shown in (Figure 3 ).

\subsection{Analytical Instrumentation}

1) High Performance Liquid Chromatography system (HPLC) (Agilent technologies 1200 series) (Avondale, PA, USA) is equipped with a $\mathrm{C}_{18}$ (YMC), $4.6 \times$ $150 \mathrm{~mm}$ diameter with $3 \mu \mathrm{m}$ column (Phenomenex-USA) using a diode array detector.

2) Scanning electron microscope (SEM): scanning electron microscope (SEM) (LEO model EVO50XVP, Carl Zeiss AG-EVO ${ }^{\circledR} 50$ Series, Germany).

\subsection{Analytical Method}

In batch reactor system, samples of $2 \mathrm{~mL}$ were taken at determined time intervals. Samples of photocatalysis/ $\mathrm{TiO}_{2}$ powder experiments were filtered through a $0.2 \mu \mathrm{m}$ filters to remove $\mathrm{TiO}_{2}$ particles. Changes in the concentration of each drug were observed from its characteristic absorption at selected nm, using HPLC system through the following method:

- Column: $\mathrm{C}_{18}$ (YMC), $4.6 \times 150 \mathrm{~mm}$ diameter with $3 \mu \mathrm{m}$.

- Mobile phase: $1 \% \mathrm{CH}_{2} \mathrm{O}_{2}(\mathrm{~V} / \mathrm{V})$ : $\mathrm{ACN}(60: 40)$.

- Wavelength: $350 \mathrm{~nm}$.

- Flow rate: $1.0 \mathrm{~mL} / \mathrm{min}$.

- Injected volum: $20 \mu \mathrm{L}$.

\subsection{Characterization of the Pilkington Active ${ }^{\mathrm{TM}}$ Blue Glass}

The elemental analysis for the grafted $\mathrm{TiO}_{2}$ thin Pilkington blue glasses was performed by using scanning electron microscope. Some cross sections obtained from the Pilkington Active ${ }^{\mathrm{TM}}$ Blue glass were analyzed. The thin sections were

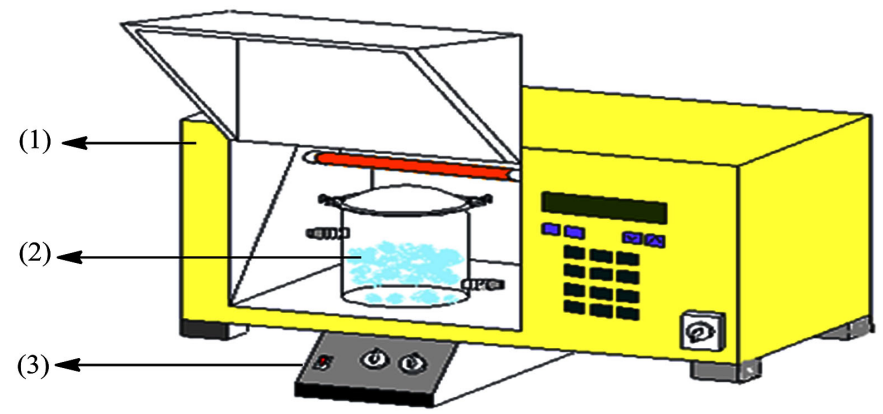

Figure 3. A schematic drawing of the batch reactor system: (1) Suntest CPS Solar Simulator, (2) Pyrex batch reactor and (3) Magnetic stirrer device. 
coated with a $30 \mathrm{~nm}$-thick carbon films. Semi quantitative analyses of the elemental composition of the different layers were obtained using a Ge ED Oxford-Link detector equipped with a Super Atmosphere Thin Window. Operating conditions of the SEM were: $15 \mathrm{kV}$ accelerating potential, $500 \mathrm{pA}$ probe current and about $10 \mathrm{~mm}$ of working distance (WD).

Thin sections of glass were prepared by the Department of Health and Environmental Science, Bari University. Samples were embedded in resin epoxy plugs and then polished.

\subsection{Photolysis and Photocatalysis Procedures}

\subsubsection{Photolysis}

Photochemical experiments were conducted by using the solar irradiation system. Working solutions of MCPA sodium monohydrate $\left(25 \mathrm{mg} \cdot \mathrm{L}^{-1}\right)$ were prepared when used by dilution form stock solution $\left(100 \mathrm{mg} \cdot \mathrm{L}^{-1}\right)$. To investigate the effect of hydrolysis, the same experiment in the dark was performed. The tests were carried out with extreme care to ensure uniform experimental conditions during the degradation kinetics. At determined time intervals, samples of $2.0 \mathrm{~mL}$ were taken and immediately analyzed by HPLC system according to the analytical method mentioned above. The photolysis treatment was carried out in a glass Pyrex batch reactor. $250 \mathrm{~mL}$ from the prepared solution was placed into well-closed reactor, then placed in a radiation field inside the Suntest (solar simulator) device, which reproduces the spectral distribution of solar irradiation, the aqueous solution containing drug was mixed continuously with magnetic stirrer during the experiment.

\subsubsection{Photocatalysis}

Photocatalysis processes were carried out by using commercial $\mathrm{TiO}_{2}$ powder and $\mathrm{TiO}_{2}$ immobilized on thin blue glass.

1) Photocatalysis with $\mathrm{TiO}_{2}$ powder

Working solutions of MCPA sodium monohydrate $\left(25 \mathrm{mg} \cdot \mathrm{L}^{-1}\right)$ with 200 $\mathrm{mg} \cdot \mathrm{L}^{-1} \mathrm{TiO}_{2}$ were prepared, $250 \mathrm{~mL}$ of the solution was placed into well-closed reactor, then placed in a radiation field inside the Suntest (solar simulator) device. At specific time intervals, samples of $2.0 \mathrm{~mL}$ were taken and immediately filtered through a $0.2 \mu \mathrm{m}$ filter, and analyzed by HPLC system according to the analysis method mentioned above. The aqueous solution containing drug was mixed continuously with magnetic stirrer during the experiment.

2) Photocatalysis with immobilized $\mathrm{TiO}_{2}$ on thin blue glass

As in the previous sections, solution of $25.0 \mathrm{mg} \cdot \mathrm{L}^{-1}$ was prepared, and then $250 \mathrm{ml}$ transferred to the glass pyrex reactor, before that the blue glass had been placed vertically on the perimeter of the inner wall of the glass pyrex batch reactor, then transferred to the suntest CPS (solar simulator) device, and exposed to the solar irradiation with continues mixing using magnetic stirring, samples were taken ( $2 \mathrm{~mL}$ for each sample) at determined intervals then filtered and injected in HPLC system according to the analysis method mentioned above. 


\subsection{Kinetics Study}

The knowledge of reaction order is essential for finding the accurate integrated rate equation. By trying to fit data of various integrated rate equations, it is possible to verify the reaction order. Kinetic parameters were calculated using integrated equations describing zero-, first- and second- (Langmuir-Hinshelwood) order equations. The determination coefficient $\left(R^{2}\right)$ was used to check the best fit.

Kinetic parameters (reaction order $(n)$, determination coefficient $\left(R^{2}\right)$, half-life $\left(t_{1 / 2}\right)$, kinetic constant $(k)$ were obtained by linear regression of logarithmic concentration values determined as a function of time according to the following equations [15] [16].

$$
\begin{aligned}
\text { Zero-order: } C_{t} & =C_{0}-k t \\
\text { First-order: } & \operatorname{Ln} C_{t}=\operatorname{Ln} C_{0}-k t \\
\text { Second-order: } & C_{0} / C_{t}=1+\left(1 / t_{1 / 2}\right) t
\end{aligned}
$$

\section{Results and Discussion}

\subsection{Characterization of Pilkington Active ${ }^{\mathrm{TM}} \mathrm{TiO}_{2}$ Coated Blue Glass}

(Figure 4) shows the SEM image of the cross section sample of the Blue glass, where the thickness of $\mathrm{TiO}_{2}$ film was found to be $397.2 \mathrm{~nm}$. (Figure 5) displays the fine-tooth comb geometry of $\mathrm{TiO}_{2}$ coating on the Blues glass surface.

As shown in (Table 1), $\mathrm{TiO}_{2}$ is a component present only on the glass surface along with other metal oxides such as iron oxide, while in the core glass it is absent and other metal oxides are countable. As reported in the Pilkington patent [17], cobalt oxide is present in low amounts (less than $75 \mu \mathrm{g} / \mathrm{g}$ ) but it was not detectable by surface analysis used. Cobalt oxide may confer the blue color to the glass.

\subsection{Preliminary Experiments}

Preliminary experiments in the dark showed that the drug dissolved in aqueous solution with and without catalyst after 48 hours was stable and no reactivity was observed at all.

\subsection{Photolysis and Photocatalysis Processes}

Figure 6 represents the behavior of photolysis and photocatalysis reactions. Removal of MCPA sodium monohydrate during photolysis experiment was very poor, only $12 \%$ from its initial concentration has been removed after 27 hours with half life equal 115.5 hours. Using immobilized $\mathrm{TiO}_{2}$ glass slaps in the photocatalytic degradation experiments accelerate to some extent the degradation rate, about $40 \%$ of initial concentration was removed after 27 hours with half life equal to 37.3 hours as shown in Table 2. But in general, the degradation rate is still substandard. 
Table 1. EDX analysis of the glass surface coated with $\mathrm{TiO}_{2}$, compared to the glass core composition.

\begin{tabular}{|c|c|}
\hline \multicolumn{2}{|c|}{$\begin{array}{l}\text { Elemental composition of the grafted surface } \\
\text { Energy: } 6.686 \mathrm{KeV} \text {, Counts: } 250\end{array}$} \\
\hline Elements & wt. $\% \pm \mathrm{SD}$ \\
\hline $\mathrm{O}$ & $44.4 \pm 0.1$ \\
\hline $\mathrm{Si}$ & $38.6 \pm 0.1$ \\
\hline $\mathrm{Na}$ & $6.0 \pm 0.0$ \\
\hline $\mathrm{Ca}$ & $5.5 \pm 0.0$ \\
\hline $\mathrm{Mg}$ & $2.4 \pm 0.0$ \\
\hline $\mathrm{Ti}$ & $1.5 \pm 0.0$ \\
\hline K & $0.3 \pm 0.0$ \\
\hline $\mathrm{Al}$ & $0.3 \pm 0.0$ \\
\hline $\mathrm{Fe}$ & $0.3 \pm 0.0$ \\
\hline \multicolumn{2}{|c|}{ Elemental composition of the core glass } \\
\hline Elements & wt. $\% \pm$ SD \\
\hline $\mathrm{O}$ & $47.2 \pm 0.1$ \\
\hline $\mathrm{Si}$ & $36.2 \pm 0.1$ \\
\hline $\mathrm{Na}$ & $4.3 \pm 0.0$ \\
\hline $\mathrm{Ca}$ & $6.0 \pm 0.1$ \\
\hline $\mathrm{Mg}$ & $2.4 \pm 0.0$ \\
\hline Sn & $2.1 \pm 0.1$ \\
\hline K & $0.3 \pm 0.0$ \\
\hline $\mathrm{Al}$ & $1.0 \pm 0.0$ \\
\hline $\mathrm{Fe}$ & $0.4 \pm 0.1$ \\
\hline $\mathrm{Cl}$ & $0.1 \pm 0.0$ \\
\hline
\end{tabular}

Table 2. Kinetic parameters of the photolysis, photocatalysis using $\mathrm{TiO}_{2}$ and photocatalysis using $\mathrm{TiO}_{2}$ immobilized system for MCPA sodium monohydrate. $k$. rate constant, $R^{2}$ : correlation coefficient, $t_{1 / 2}$ : half-life.

\begin{tabular}{ccccc}
\hline Conditions & Order & $K\left(\mathrm{~min}^{-1}\right)$ & $\boldsymbol{R}^{2}$ & $\boldsymbol{t}_{1 / 2}(\mathrm{~min})$ \\
\hline Photolysis & 1 & 0.0001 & 0.960 & 6931.5 \\
Photocatalysis/TiO 2 powder & 1 & 0.019 & 0.914 & 36.5 \\
Photocatalysis/ $\mathrm{TiO}_{2}$ immobilized & 1 & 0.00031 & 0.960 & 2236.0 \\
\hline
\end{tabular}

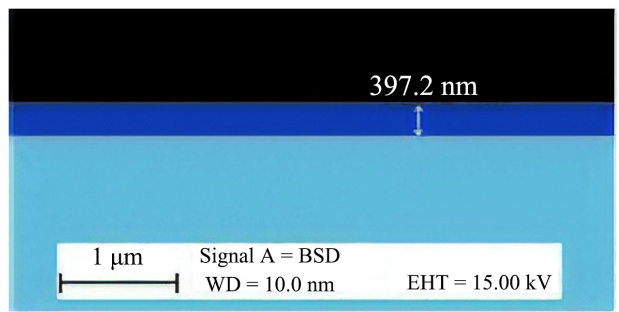

Figure 4. SEM colored micrograph of the Blue glass cross section showing the $\mathrm{TiO}_{2}$ layer immobilized on the glass surface. 


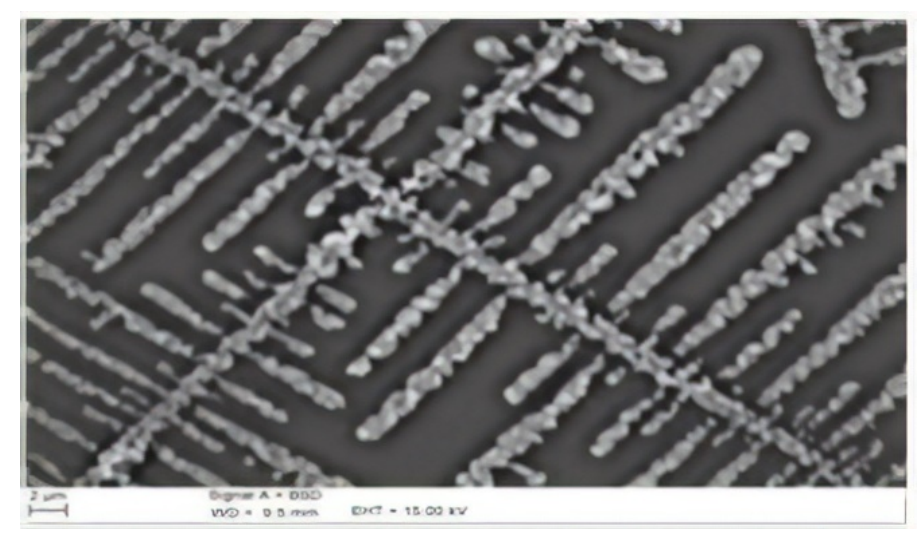

Figure 5. SEM micrograph of the Blue glass surface showing the fine-tooth comb of $\mathrm{TiO}_{2}$ coating.

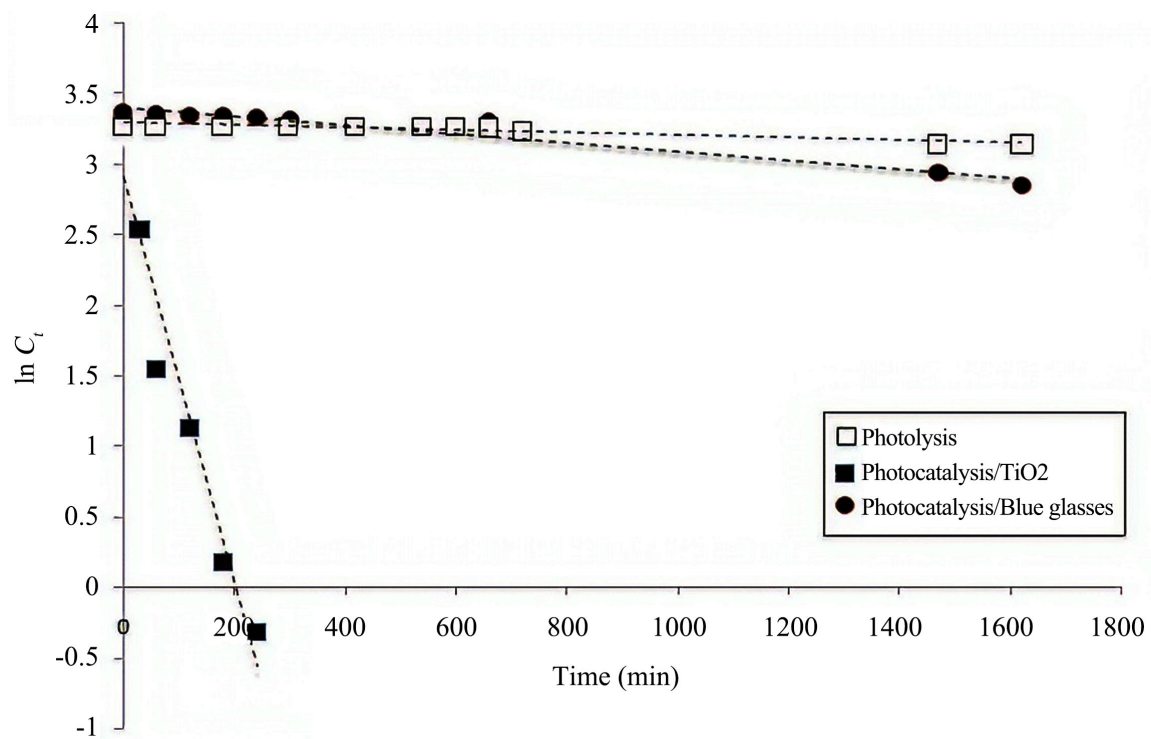

Figure 6. Time course mineralization of MCPA sodium monohydrate at $25 \mathrm{mg} / \mathrm{L}$ initial concentration in batch reactor (photolysis, photocatalysis) solar (lamp Heraeus TNN 15/32). Experimental conditions: MCPA sodium monohydrate concentration $=25 \mathrm{mg} / \mathrm{L}$, $\left[\mathrm{TiO}_{2}\right]=200 \mathrm{mg} / \mathrm{L}$, solar intensity (sunny day) $=500 \mathrm{Wm}^{2}$.

While, using $\mathrm{TiO}_{2}$ dispersed powder to the photocatalytic process accelerated the degradation process dramatically (half-life $=36.5 \mathrm{~min}$ and complete mineralization in about 4 hours).

The knowledge of reaction order is essential for finding the accurate integrated rate equation. By trying to fit data of various integrated rate equations, it is possible to verify the reaction order. Kinetic parameters were calculated using integrated equations describing zero-, first- and second- (Langmuir-Hinshelwood) order equations. The determination coefficient $\left(R^{2}\right)$ was used to check the best fit.

The photo-degradation for MCPA sodium monohydrate plotted as the natural logarithm of the ratios of the observed over the initial concentrations, exhibited approximately liner behavior. From the overall results, a comparative kinetic study 
was carried out for the chemical process with photolysis and with photocatalysis. Initial mineralization rate constants $(k)$ were determined, for all processes, from the slope of (ln $C A_{(t)}$ ) vs $t$ (time) plots where $C A_{(t)}$ are MCPA sodium monohydrate concentration at time $\mathrm{t}$. It is also presented the half-life times $(t)$, i.e. the time necessary to reduce $50 \%$ of initial MCPA sodium monohydrate concentration for each process. The half-life times are determined by interpolation from experimental data (Table 2).

\subsection{Identification of Transient Photoproducts}

Determining the transient photoproducts that resulted from degradation processes is very important, since some of these photoproducts could be more toxic than the parent compound accordingly. Previous studies and literatures related to possible pathways of MCPA photo degradation have focused on the expected photoproducts.

According to Topalov et al. (2001 and 2003), the photo assisted oxidative degradation of MCPA in the presence of $\mathrm{TiO}_{2}$ involves formation of a variety of intermediate species. In these studies the NMR analysis of suspensions of $\mathrm{TiO}_{2}$ containing MCPA was performed and the proton NMR spectral profiles were monitored on a Bruker AC-250 instrument, and ${ }^{13} \mathrm{C}$ NMR spectra were recorded by the same instrument. The results suppose that degradation pathway followed the hydroxylation of the aromatic ring and chloride. Accordingly, the degradation of the parent MCPA molecule yields the formation of 4-chloro-2-methylphenol, by elimination of $\mathrm{CO}_{2}$ and $\mathrm{H}_{2} \mathrm{O}$ as shown in (Table 3). Further transformations of the aromatic ring are possible by the chlorine substitution with hydroxyl group, or by electrophilic addition of the $\mathrm{OH}$ radical [14] [18].

Table 3. Proposed photoproduct of MCPA.

4-chloro-2-methylphenylmethanoate




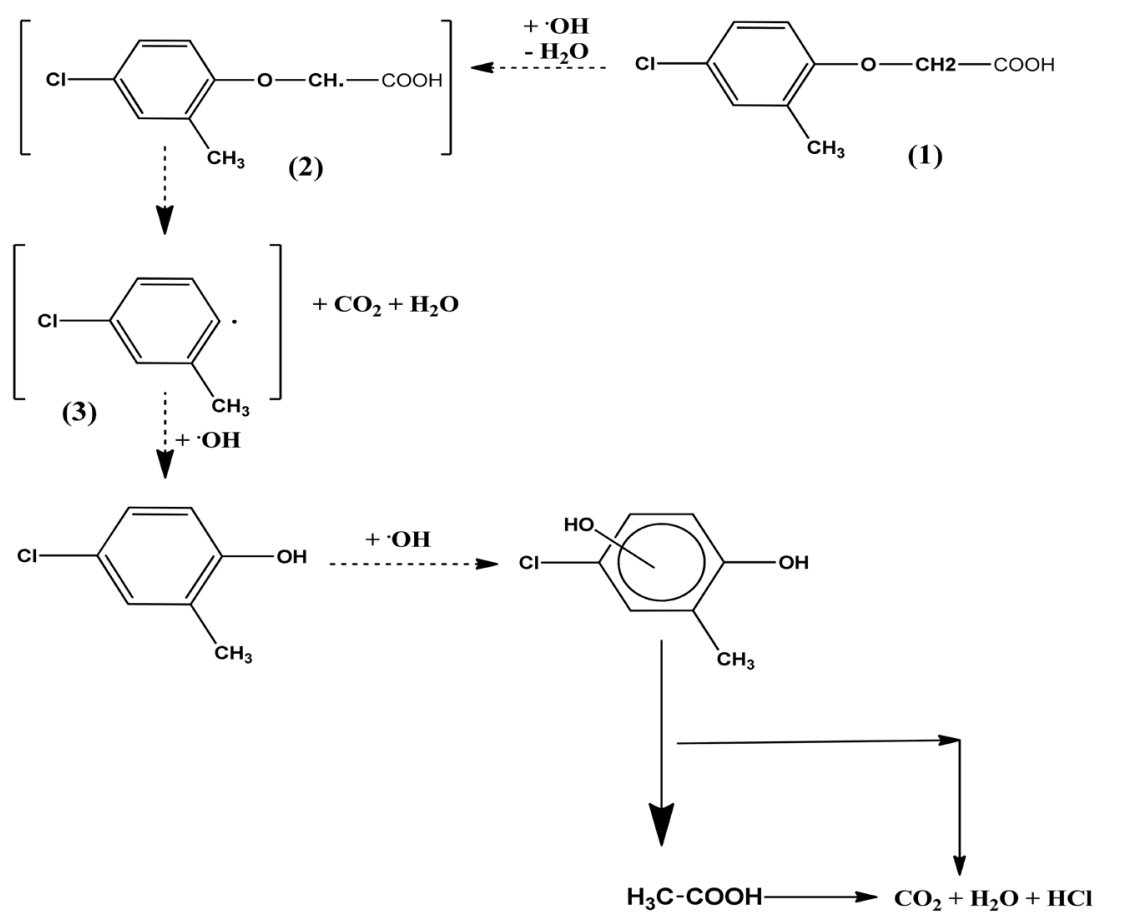

(4)

(Complete mineralization)

Figure 7. Possible pathway of MCPA photodegradation in the presence of $\mathrm{TiO}_{2}$.

As a result of degradation of the aromatic part of the MCPA molecule, acetic acid is formed. By further action of $\mathrm{OH}$ radicals, acetic acid is decomposed into $\mathrm{CO}_{2}$ and $\mathrm{H}_{2} \mathrm{O}$ [17] [19] [20]. Hydroxyl radicals continued the attacking of the substrate caused hydroxylation products, and finally the opening of the ring yielding $\mathrm{CO}_{2}$ and $\mathrm{H}_{2} \mathrm{O}$ as presented in Figure 7 [14] [18].

\section{Conclusion}

The results exhibited that solar light alone was insufficient to achieve a complete and fast removal for MCPA sodium monohydrate herbicide. While using titanium dioxide as a catalyst either as a powder or in immobilized form accelerated the photodegradation rate. Although $\mathrm{TiO}_{2}$ in the powder form gives faster degradation rate but this is requires a post treatment stages to recover the catalyst from the reaction mixture. For that using $\mathrm{TiO}_{2}$ immobilized system over blue glass slabs could be promising alternative to traditional titanium dioxide powder although it was showed slow degradation rate. We believe that with more modifications in grafted $\mathrm{TiO}_{2}$ thin blue glasses such as increasing the concentration of $\mathrm{TiO}_{2}$ on the sheets surfaces or changing the amount of oxides in the blue glasses the effectiveness of these substrates will be improved. All photo-degradation processes have followed a first order kinetic with $t_{1 / 2} 36.5 \mathrm{~min}$ for photocatalysis $\left(\mathrm{TiO}_{2}\right.$ powder), $2236 \mathrm{~min}$ for photocatalysis $\left(\mathrm{TiO}_{2}\right.$ immobilized) and $6931.5 \mathrm{~min}$ for photolysis process. The main intermediate obtained is 4-chloro-2-methylphenol. 


\section{Acknowledgements}

This work was supported by the European Commission in the framework of the Project "Diffusion of nanotechnology based devices for water treatment and recycling- NANOWAT” (ENPI CBC MED I.B/2.1/049, Grant No. 7/1997).

\section{Conflicts of Interest}

The authors declare no conflicts of interest regarding the publication of this paper.

\section{References}

[1] Pena, A.L.S. and Silveria, I.J. (1997) Determination of Chlorophenoxy Herbicides in Waters by Capillary Gas Chromatography with Ion Trap Detection. Journal of Chromatography A, 758, 324-331. https://doi.org/10.1016/S0021-9673(96)00732-7

[2] Alromeed, A., Scrano, L., Bufo, S. and Undabeytia, T. (2015) Slow Release Formulations of the Herbicide MCPA by Using Clay-Protein. Pest Management Science, 71, 1303-1310. https://doi.org/10.1002/ps.3929

[3] Carabias-Martinez, R., Rodriguez-Gonzalo, E., Fernandez-Laespad, M.E., Calvo-Seronero, L. and Sanchez-San Roman, F.J. (2003) Evolution over Time of the Agricultural Pollution of Waters in an Area of Salamanca and Zamora (Spain). Water Research, 37, 928-938. https://doi.org/10.1016/S0043-1354(02)00366-4

[4] Guzzella, L., Pozzoni, F. and Giuliano, G. (2006) Herbicide Contamination of Surficial Groundwater in Northern Italy. Environmental Pollution, 142, 344-353.

https://doi.org/10.1016/j.envpol.2005.10.037

[5] European Commission Directive EC 1107/2009 of 21 October 2009 Concerning the Placing of Plant Protection Products on the Market and Repealing Council Directives 79/117/EEC and 91/414/EEC.

[6] Badawy, M.I., Ghaly, M.Y. and Gad-Allah, T.A. (2006) Advanced Oxidation Processes for the Removal of Organophosphorus Pesticides from Wastewater. Desalination, 194, 166-175. https://doi.org/10.1016/j.desal.2005.09.027

[7] Konstantinou, I.K. and Albanis, T.A. (2003) Photocatalytic Transformation of Pesticides in Aqueous Titanium Dioxide Suspensions Using Artificial and Solar Light: Intermediates and Degradation Pathways. Applied Catalysis B, 42, 319-335. https://doi.org/10.1016/S0926-3373(02)00266-7

[8] Litter, M.I. (2005) Introduction to Photochemical Advanced Oxidation Processes for Water Treatment, Vol. 2. Springer-Verlag, Berlin, 325-366. https://doi.org/10.1007/b138188

[9] Phanikrishna Sharma, M.V., DurgaKumari, V. and Subrahmanyam, V.M. (2008) $\mathrm{TiO}_{2}$ Supported over SBA-15: An Efficient Photocatalyst for the Pesticide Degradation Using Solar Light. Chemosphere, 73, 1562-1569. https://doi.org/10.1016/j.chemosphere.2008.07.081

[10] Zhu, X., Yuan, C., Bao, Y., Yang, J. and Wu, Y. (2005) Photocatalytic Degradation of Pesticide Pyridaben on $\mathrm{TiO}_{2}$ Particles. International Nano Letters, 229, 95-105. https://doi.org/10.1016/j.molcata.2004.11.010

[11] Okamoto, K.I., Yamamoto, Y., Tanaka, H. and Tanaka, M. (1985) Heterogeneous Decomposition of Phenol over $\mathrm{TiO}_{2}$ Powder. Bulletin of the Chemical Society of Japan, 58, 2015-2022. https://doi.org/10.1246/bcsj.58.2015

[12] Wu, C. (2008) Effects of Operational Parameters on the Decolorization of C.I. Reac- 
tive Red 198 in UV/TiO ${ }_{2}$-Based System. Dyes and Pigments, 77, 31-38. https://doi.org/10.1016/j.dyepig.2007.03.003

[13] Gray, N. (1996) Pesticides and Organic Micropollutants. In: Drinking Water Quality, Wiley, Chichester, 132-148.

[14] Topalov, A., Molnár-Gábor, D., Abramovic, B., Korom, S. and Pericin, D. (2003) Photocatalytic Removal of the Insecticide Fenitrothion from Water Sensitized with $\mathrm{TiO}_{2}$. Journal of Photochemistry and photobiology, 160, 195-201. https://doi.org/10.1016/S1010-6030(03)00266-1

[15] Scrano, L., Bufo, S.A., Perucci, P., Meallier, P. and Mansour, M. (1999) Photolysis and Hydrolysis of Rimsulfuron. Pesticide Science, 55, 955-961. https://doi.org/10.1002/(SICI)1096-9063(199909)55:9<955::AID-PS29>3.0.CO;2-9

[16] Scrano, L., Bufo, S.A., Emmelin, C. and Meallier, P. (2005) Abiotic Degradation of the Herbicide Rimsulfuron on Minerals and Soil. In: Lichtfouse, E., Schwarzbauer, J. and Robert, D., Eds., Environmental Chemistry: Green Chemistry and Pollutants in Ecosystems, Springer, Berlin, 505-515. https://doi.org/10.1007/3-540-26531-7_46

[17] Sheel, D.W., McCurdy, R.J. and Hurst, S.J. (1998) Method of Depositing Tinoxide and Titanium Oxide Coatings on Flat Glass and the Resulting Coated Glass. Patent Application WO 98/06675.

[18] Topalov, A., Abramovic, B., Molnar-Gabor, D., Csanadi, J. and Arcson, O. (2001) Photocatalytic Oxidation of the Herbicide (4-Chloro-2-Methylphenoxy)acetic Acid (MCPA) over $\mathrm{TiO}_{2}$. Journal of Photochemistry and Photobiology A: Chemistry, 140, 249-253. https://doi.org/10.1016/S1010-6030(01)00415-4

[19] Mylonas, A., Roussis, V. and Papaconstatinou, E. (1996) Photocatalytic Degradation of Phenol and p-cresol by Polyoxotungstates, Mechanistic Implications. Polyhedron, 95, 3211-3217. https://doi.org/10.1016/0277-5387(96)00034-4

[20] Mylonas, A., Hiskia, A. and Papaconstantinou, E. (1996) Contribution to Water Purification Using Polyoxometalates Aromatic Derivatives, Chloroacetic Acids. Journal of Molecular Catalysis A: Chemical, 114, 191-200.

https://doi.org/10.1016/S1381-1169(96)00317-2 